\title{
Filman los hijos. Nuevo testimonio en los documentales En algún lugar del cielo de Alejandra Carmona y Mi vida con Carlos de Germán Berger-Hertz
}

\author{
María Teresa Johansson \\ Universidad Alberto Hurtado \\ mtjohans@uahurtado.cl \\ Constanza Vergara \\ Universidad Alberto Hurtado \\ cvergara@uahurtado.cl
}

RESUMEN: En este artículo se estudia el nuevo testimonio audiovisual de miembros de la segunda generación o generación de hijos de padres víctimas de la dictadura en Chile. Se analizan los documentales En algún lugar del cielo (Alejandra Carmona, 2003) y Mi vida con Carlos (Germán Berger-Hertz, 2009) y se propone que en ellos se producen desplazamientos respecto de la práctica narrativa de la generación anterior: se observa una nueva posición de testigo en continuo movimiento y la presencia de imágenes más cotidianas y familiares. Asimismo, estos documentales realizan un entrecruzamiento entre la biografía de los padres y la autobiografía de los hijos. A partir de los rasgos performáticos de este tipo de discurso, se analiza la posibilidad de elaboración del proceso de duelo y de transmisión intergeneracional.

Palabras Clave: memoria, testimonio, documental. 


\section{The sons Shoot. NeW Testimony in the Documentaries EN ALGÚN LUGAR DEL CIELO By AlejandRa CARMONA and Mi Vida con Carlos by Germán Berger-Hertz}

ABSTRACT: This paper analyses the new audiovisual testimony, made by members of the second generation, sons and daughters of parents who were victims of the Chilean dictatorship. It discusses two documentaries: En algín lugar del cielo (Alejandra Carmona, 2003) and Mi vida con Carlos (Germán Berger-Hertz, 2009), and posits that there are changes regarding the narrative practice of the previous generation: a new position for the witness is noted, and there are more daily and familiar images. Also, the narrative of the film intersects the parents' biographies and the children's autobiographies. From the performative features of this type of discourse, the paper explores the elaboration of the grieving process and the intergenerational transmission.

KEYWORDS: memory, testimony, documentary.

En los últimos años, las producciones culturales de la segunda generación o generación de hijos de las víctimas de la dictadura han supuesto una transformación de los discursos sobre nuestro pasado reciente. Los documentales En algún lugar del cielo, de Alejandra Carmona (2003), y Mi vida con Carlos, de Germán Berger-Hertz (2009), se inscriben en este campo de nuevos discursos de la memoria de la dictadura. En medio del silencio familiar y el distanciamiento, ellos emprenden un proyecto que pone en marcha una elaboración de esa memoria traumática y del duelo. A partir de la interrogación del álbum fotográfico familiar y recurriendo a la entrevista a cercanos llevarán a cabo un proceso de búsqueda personal que también involucra una experiencia colectiva. En estos documentales aparece una nueva posición testimonial de quienes fueron víctimas de la represión dictatorial: se trata de dos hijos de padres asesinados que elaboran un proceso de duelo por la figura paterna y que relatan una experiencia personal de exilio y retorno, mediante una serie de desplazamientos constantes ${ }^{1}$.

1 Esta nueva posición de enunciación no solo es observable en la producción documental, sino también en el ámbito narrativo y dramático. Ejemplos de esto son: 
Estos documentales manifiestan que el género testimonial ha transitado desde el discurso narrativo-literario, escrito preferentemente por la generación anterior, hacia un testimonio audiovisual, que escenifica una nueva posición de enunciación y trabaja una diversidad de procedimientos, como acentuar el carácter performático del discurso o reinsertar la imagen y la historia de sus padres en la vida pública. A partir de lo anterior, se constata la irrupción del documental como nuevo soporte para las producciones culturales sobre la memoria de las violaciones a los derechos humanos. El medio audiovisual también hace aparecer nuevas operaciones en torno a las materialidades del recuerdo que no son privativas de una segunda generación, sino que pueden entenderse como un fenómeno transgeneracional. Así lo confirma un amplio número de realizadores, quienes producen elaboraciones del pasado colectivo reciente a través de discursos anclados en sucesos personales. Elizabeth Ramírez da cuenta de este itinerario, cuando señala que los documentales de la generación de la postdictadura se han centrado en mundos privados:

Al mismo tiempo, sin embargo, surgirían las narraciones de tono más reflexivo e intimista, articuladas desde el "yo", por realizadores que estuvieron involucrados de alguna u otra manera en la lucha política de los setenta. En sus documentales buscarían establecer vínculos entre la memoria individual y la colectiva como es evidente en La Flaca Alejandra (1993) de Carmen Castillo y, algunos años más tarde (aunque todavía con un gran interés en la figura de lo colectivo), Chile, La Memoria Obstinada (1997) de Patricio Guzmán (50).

En la reciente producción audiovisual de nuestro país es posible reconocer la presencia de un importante número de documentales autobiográficos de carácter testimonial. Los primeros antecedentes se remontan a los años ochenta, y se refieren a la temática del exilio y el retorno. Esa es la situación de Diario inconcluso, de Marilú Mallet (1982); Fragmentos de un diario inacabado, de Angelina Vázquez (1983); y Eran unos que venían de Chile, de Claudio Sapiaín (1989). A esos tempranos antecedentes se sumará una abundante producción durante la postdictadura: Salvador Allende, de Patricio Guzmán

Fuenzalida (2012), de Nona Fernández, y El año en que nací (2012), de Lola Arias, entre otros. 
(2004); Héroes Frágiles, de Emilio Pacull (2006); La ciudad de los fotógrafos, de Sebastián Moreno (2006); Reinalda del Carmen, mi mamá y yo, de Lorena Giachino (2006); Calle Santa Fe, de Carmen Castillo (2007); El edificio de los chilenos, de Macarena Aguiló (2010), y El eco de las canciones, de Antonia Rossi (2010) $)^{2}$.

Las dos películas que analizamos en este texto forman parte de ese corpus mayor y también comparten características particulares, a saber, la pérdida del padre a corta edad, la experiencia del exilio y el retorno, y la restitución de la figura paterna en un proceso de duelo inconcluso. Ambos documentales entrecruzan la autobiografía de los hijos/directores con la biografía de los padres asesinados. Asimismo, llevan a cabo una investigación en el contexto familiar o cercano, que se enmarca en la experiencia colectiva de la dictadura. Aunque se recurra a algunas imágenes del archivo noticioso, no aparecen opiniones de especialistas ni hay voces de autoridad que cuenten o expliquen el pasado; esta tarea está reservada al círculo íntimo conformado por madres, tíos o compañeros de los padres.

En algún lugar del cielo es un documental autobiográfico en el que Alejandra Carmona reconstruye la figura de su padre y reelabora su propia experiencia del exilio y el retorno. Presente a través de la voz en off y de su aparición ante la cámara, Carmona entrelaza un relato en el que se mueve entre distintos tiempos, lugares y tipos de imágenes. Exiliada junto a su madre en la ex RDA, Alejandra mostrará escenas de su infancia como pionera en la escuela Salvador Allende y reconstruirá el momento en que se entera de la muerte de su padre. También mezclará sus reflexiones con las de otros de su misma generación quienes, como ella, han vivido la experiencia del exilio y se sienten desarraigados. El pasado se narra entre Santiago, Berlín y Barcelona, y también se muestra en una diversidad de formatos fílmicos: Súper-8, 16 milímetros, video y archivo de prensa. La directora afirma que "el encuentro con mi padre solo puede tener lugar en Chile". Ese motivo, sumado a su propia maternidad y el deseo de que su hija esté más cerca del país de su primera infancia, hacen que Carmona

2 Esta proliferación de documentales autobiográficos ha estado acompañada de una abundante reflexión crítica. Además del citado artículo de Elizabeth Ramírez, en 2011 se publicó un dossier de la revista La Fuga titulado "Interiores", y han escrito sobre el tema, entre otros: Paola Lagos, Catalina Donoso, Bernardita Llanos, Claudia Barril, y Michelle Bossy y Constanza Vergara. 
regrese a Santiago y emprenda este proyecto, el que está enmarcado en la conmemoración de los treinta años del golpe militar.

Mi vida con Carlos, por su parte, también es un documental autobiográfico en el que escuchamos la voz del director y vemos su presencia ante la cámara. En este caso, la historia se articula a partir del asesinato de Carlos Berger a manos de la Caravana de la Muerte y del imposible reencuentro entre padre e hijo. La voz en off de Germán Berger-Hertz narra en modo epistolar, refiriéndose apelativamente a su padre desaparecido e inscribiendo el relato en un ámbito privado: "querido papá... te quiere siempre, Germán”. En este caso, la reconstrucción de la historia privada también implica continuos desplazamientos y saltos temporales pero, a diferencia del documental de Carmona, esta vez los testimonios quedan reducidos al ámbito estrictamente familiar y no se incluye a otros contemporáneos del director que den cuenta de una experiencia colectiva ${ }^{3}$.

Antes del análisis de las dos producciones, quisiéramos plantear algunas premisas que permiten conceptualizar el documental autobiográfico -así como la relación entre este género y la autobiografía- y el testimonio literario. A partir de ello, analizaremos las innovaciones de estos nuevos testimonios documentales: la puesta en escena de una nueva posición de testigo (la víctima infantil), y la exploración de las posibilidades performáticas de este tipo de discurso, respecto de la posibilidad de elaboración del duelo y de la transmisión intergeneracional.

Ambos documentales estuvieron en competencia en el Festival Internacional de Documentales de Santiago (FIDOCS), donde la película de Alejandra Carmona obtuvo el Gran Premio el año 2003. Este suceso es un antecedente relevante para otros documentales autobiográficos que han ganado posteriormente el Festival, como Remitente, una carta visual (Tiziana Panizza, 2009), El edificio de los chilenos (Macarena Aguiló, 2010), Hija (María Paz González, 2011) y Sibila (Teresa Arredondo, 2012). Si bien Mi vida con Carlos no ha recibido premios a nivel nacional, sí ha participado de un circuito más amplio que el de los festivales: ha sido exhibida dos veces por Televisión Nacional (en enero del 2012 y octubre del 2013); y ha sido mostrada en el Museo de la Memoria y en la Cineteca Nacional del CCPLM. Este año el documental ha despertado un renovado interés, porque la exitosa miniserie de Andrés Wood, Ecos del desierto (estrenada en septiembre por Chilevisión), está inspirada en la historia de los padres de Carlos BergerHertz, Carmen Hertz y Carlos Berger. 


\section{DOCUMENTAL, AUTOBIOGRAFÍA Y TESTIMONIO}

El documental autobiográfico, también referido como autoetnografía, es aquella producción audiovisual que narra en primera persona una situación de índole familiar o ligada a la esfera de lo íntimo y lo privado (Bossy y Vergara 13). A través de diversos procedimientos, el documental autobiográfico cuestionaría las presunciones de objetividad del documental tradicional, que muchas veces ha sido utilizado por las ciencias, el periodismo y otras disciplinas ocupadas en la exploración, explicación y documentación del mundo y de los sujetos (Beattie 107). Alejándose de esta tradición de registro, los first-person films permitirían "sacar a la luz todo lo que el documental tradicional reprime": la subjetividad, la muestra del proceso de producción, las dudas sobre la capacidad informativa o de conocimiento del proyecto, los errores, etcétera (Di Tella citado en Firbas $58)$.

En 1980, Elizabeth Bruss publica un artículo pionero acerca de las relaciones entre autobiografía y cine. En "Eye for I: making and unmaking autobiography in film", Bruss plantea un escenario de amenaza para las prácticas de escritura frente a la creciente importancia de los medios audiovisuales; se pregunta si el desplazamiento cultural que supone este cambio en los sistemas dominantes de comunicación no significaría la extinción de la autobiografía como la habíamos conocido hasta entonces. En ese momento, la crítica norteamericana planteaba que no existía un equivalente cinematográfico para la autobiografía, porque el medio audiovisual sería incapaz de transmitirnos el mismo valor de acto, de verdad y de identidad que el escrito.

Antes de refutar los planteamientos de Bruss, Philippe Lejeune resume sus ideas de la siguiente manera:

El cine autobiográfico parece estar condenado a la ficción (...) No puedo pedirle al texto que muestre lo que ha sido mi pasado, mi infancia, mi juventud, sólo puedo evocarlo o reconstituirlo (...) [En el cine] la falta de autenticidad del artefacto se vuelve perceptible porque, en última instancia, una cámara también hubiera podido registrar, en otro tiempo, la realidad de lo que aquí es representado por un simulacro (18-9). 
Bruss recalca la diferencia entre el medio cinematográfico y el escrito: mientras el primero es un sistema motivado de signos, es decir, tiene una relación física con la realidad representada, el segundo es arbitrario y convencional. Esta característica volvería especialmente problemático el relato retrospectivo de las experiencias. Entonces, la decisión acerca de cómo representar el pasado parece crucial: ¿acudir a material de archivo? (¿oficial o familiar?); ¿hacer reconstrucciones?; ¿obtener testimonios?; ¿ilustrar poéticamente una voz en off que evoque ese pasado?

Los críticos posteriores han refutado estas ideas de Bruss, pero también han destacado que propuso estas conclusiones antes de que se estableciera el corpus canónico de documentales autobiográficos, representado por obras de directores como Ross McElwee, Alan Berliner o David Perlov, quienes estrenan sus películas a partir de la década del ochenta. A juicio de autores como Michael Renov, Jim Lane o el propio Lejeune, procedimientos recurrentes -como el uso de la cámara subjetiva, la voz en off, la utilización de imágenes y fragmentos del archivo familiar y el registro del presente- permiten al espectador recuperar los valores de acto, verdad e identidad característicos de la autobiografía literaria.

En su carácter autobiográfico, estos documentales compartirían también otros presupuestos de la escritura literaria. Sylvia Molloy sostiene que el impulso del autógrafo implica siempre una renuncia al amparo literario de la ficción narrativa en pos de una presencia tensionada entre la escritura y el yo. El yo autobiográfico solo puede constituirse dentro del proceso escritural y en el trabajo de la memoria. Molloy describe este proceso en los siguientes términos: la autobiografía no depende de los sucesos sino de la articulación de esos sucesos, almacenados en la memoria y reproducidos mediante el recuerdo y su verbalización (18). En los documentales autobiográficos también sería posible dar cuenta de esta presencia tensionada entre el relato documental y el yo, presente tanto en la voz en off, en la continuidad narrativa de la historia de vida y en la presencia de objetos que remiten a un mundo íntimo.

Por su parte, no solo sería posible establecer relaciones entre el documental y la autobiografía, sino también entre el documental y el testimonio autobiográfico. La relación entre estos últimos géneros es más coherente en tanto comparten la primacía de una función referencial y su cualidad verista, puesto que, asociada al concepto de testimonio, se encuentra la noción de verdad. Tal como lo plantea Beatriz Sarlo en Tiempo 
pasado, el testimonio posee una cualidad ética y sostiene sus prerrogativas en la esfera pública afirmándose en la relación entre sujeto y experiencia a partir de la cual funda una comunidad al entregar una "escena para el duelo" (67). En este sentido, el testimonio no solo implica la renuncia a una autobiografía concebida como totalidad de sentido unitario, sino también la exposición fragmentaria de una identidad vulnerada, mermada por un episodio traumático a partir del cual el acto de escritura ejerce una mediación de lenguaje tenue y vulnerable. En el testimonio, el testigo se confronta con el problema de la autorrepresentación en un espacio fronterizo entre la experiencia y la narración: lo incomunicable de la vivencia da prueba de la existencia de un límite, pero también del intento de un proceso de verbalización de esa fractura biográfica. Según LaCapra: "Elaborar el trauma implica un esfuerzo por articular o volver a articular los afectos y las representaciones de un modo que tal vez nunca pueda trascender la puesta en acto o el acting out de la disociación que incapacita pero que, en cierta medida, puede contrarrestarla" (64). En Mi vida con Carlos los recurrentes silencios, planos generales y tomas en exteriores dan cuenta de ese intento por otorgarle espacio a la puesta en escena del trabajo de memoria de sus familiares. Asimismo, el uso de diferentes formatos de imagen y la resemantización del archivo familiar (fotos, cartas, grabaciones) muestra una búsqueda formal en cuanto a la articulación de la experiencia. De este modo, los documentales de carácter testimonial son justamente una posibilidad de contrarrestar la disociación mediante un trabajo que restituye afectos y representaciones.

\section{TESTIGO INFANTIL Y REINSCRIPCIÓN DE LA IMAGEN PATERNA}

Acorde con este itinerario, es posible sostener que tanto En algún lugar del cielo como Mi vida con Carlos representan nuevas operaciones en torno a la autorrepresentación, el trauma, la memoria y las posibilidades de elaboración del duelo, exponiendo tanto la fractura de una narrativa lineal como la ruptura con un tipo de testimonio que instalaba el acontecimiento represivo como un momento "excepcional" en la trayectoria de vida del autógrafo. Por el contrario, la narrativa del trauma de la violencia es, en el caso de las nuevas generaciones, constitutiva de la identidad biográfica y dilatada en el tiempo, es decir, inherente al decurso vital, puesto que 
se inscribe como marca reiterativa y temprana (casi podríamos decir, de origen) de la autobiografía. En este sentido, los documentales se integrarían a una nueva tendencia del cine autobiográfico de carácter testimonial, al configurar un nuevo tipo de testigo: una víctima infantil debe hacer una elaboración de larga data.

Es interesante constatar en estas producciones una reinscripción de la figura paterna, que compensa su anonimato y desconocimiento hasta antes del estreno de los documentales. Realizar una biografía audiovisual de los padres es hacerlos ingresar a un espacio social de reconocimiento, así como una forma de desplazar la condición de orfandad de los hijos. Este desplazamiento se produce tanto por la reposición de la imagen e historia paternas, como por la explícita relación que con ellos establecen los hijos en el presente de la enunciación. Esta característica parece contrarrestar el imaginario narrativo de la postdictadura, marcado por la presencia de personajes sin padres (como sugiere Rodrigo Cánovas).

El documental de Alejandra Carmona empieza remarcando la posición del testigo infantil: se trata de un retorno al momento en que se entera de la muerte del padre en Berlín, en 1977: "Ese día mi vida cambió para siempre" dice la voz en off de la directora, mientras vemos una reconstrucción con cámara subjetiva que atraviesa la entrada del edificio donde vivía entonces. Asimismo, el comienzo de Mi vida con Carlos también manifiesta desde la primera escena la posición de víctima infantil y el deseo de restituir la historia del padre. Vemos a Carlos Berger entrando (ver figura 1) al mar mientras escuchamos: "La primera vez que te vi fue en esta imagen de Súper-8. Nunca vi tu cuerpo en movimiento o más bien, no lo recuerdo. No podría recordarte, porque nadie me habló nunca de ti, tenía un año cuando te mataron y tú tenías treinta. Cuando yo cumplí los treinta años me di cuenta de lo joven que eras, de lo mucho que te faltaba por vivir. Quise saber quién habías sido". 


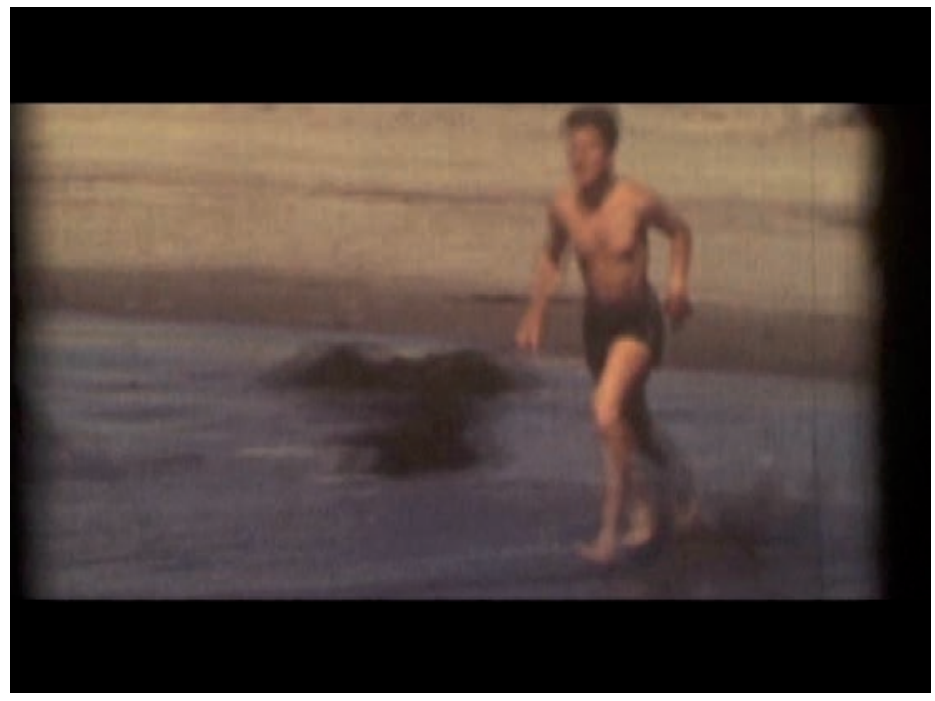

Figura 1. Mi vida con Carlos, de Carlos Berger-Hertz

$\mathrm{Al}$ igual que Mi vida con Carlos, el documental de Carmona lleva a cabo un periplo "detectivesco", en el que el retorno a Chile para encontrarse con el padre implica reconstruir su muerte. La directora dice "sólo conozco fragmentos de la vida de mi padre... Ahora me pregunto, ¿quién era él realmente?, ¿`ómo era su vida en la clandestinidad?, ¿cómo pudo soportar el miedo y el acoso hasta el final?". Al recomponer los últimos pasos de su padre y volver a visitar los lugares donde estuvo, Alejandra duplica esa identidad e incluye al espectador en esa operación. El documental refiere entonces lo sucedido a Augusto Carmona en un gesto por erradicarlo del anonimato, reinstalando su imagen y su historia en el espacio público.

En cierta medida, es posible postular que Augusto Carmona replica el lugar de Rodolfo Walsh, imagen ya mitificada del escritor comprometido. Walsh, argentino y periodista militante de Montoneros, también hace de la clandestinidad su ejercicio y su lugar de enunciación. El documental es enfático en declarar que la clandestinidad fue un estado de vida durante los últimos años de Carmona y que desde ahí dirigía el periódico El Rebelde, frente de prensa del MIR. Asimismo, especifica que la ocupación de Carmona era justamente sostener un medio de comunicación militante. Las armas, al modo de Rodolfo Walsh, son la máquina de escribir y los "papelitos" que había que trasladar con información. El "violento oficio 
de escribir" de la labor periodística se realiza en la clandestinidad con un cambio de nombre y apariencia. Queda como una promesa incumplida para el espectador la posibilidad de leer los escritos de Carmona, ya que, aunque vemos algunas tarjetas y se lo caracteriza como un "escritor incansable", las cartas que envió quedan protegidas en la intimidad de la relación entre padre e hija ${ }^{4}$.

La cámara regresa a la escena del crimen y repite los últimos momentos de la vida de Augusto Carmona, quien, de manera ingenua y por una acción de lealtad con un amigo entrañable, vuelve a su casa después de un contacto que no había llegado, exponiéndose a la muerte. El testimonio del vecino Marchant y el recorrido de la cámara llevan al espectador al encuentro con esa emboscada, lo que condensa la tensión del relato. Sin embargo, en esa reconstitución del asesinato de Carmona no hay seres humanos; solo queda la materialidad del lugar: la calle Barcelona y la cámara. El "aquí", en la palabra del vecino que ha visto la escena, marca el espacio como un lugar de memoria.

\section{DESPLAZAMIENTOS Y ELABORACIÓN DE LA MEMORIA}

El trayecto hacia el reencuentro con el padre implica para los directores necesariamente emprender un recorrido hacia otras geografías y, por lo tanto, una diversificación de los lugares de rodaje: viajes desde Barcelona y Berlín a Santiago; de Santiago a Ottawa; de Berlín a Barcelona; de Santiago a Calama. El montaje acentúa esta sensación de discontinuidad espacial y temporal, porque vemos planos yuxtapuestos y desordenados del exilio y el retorno, desplazamientos que dibujan un mapa que es el resultado de las piezas diseminadas tras el estallido del golpe militar. A este respecto dice Carmona: "mi vida y la de muchos de mis amigos fue un continuo ir y venir. Fueron historias que recomenzaron una y otra vez". Esta problemática de los lugares queda plasmada también en los planos que muestran a ambos

4 El documental abre la posibilidad de contar con una antología de los textos de Carmona que, además de recoger parte del epistolario a su hija, podría contener textos históricos como el reportaje realizado en Bolivia a la guerrilla. 
directores en el aeropuerto: el no-lugar desde el cual se recibe o se despide a los seres queridos.

En una conferencia sobre cineastas argentinos de la generación de hijos, dictada en abril de 2011 en la Universidad de Santiago de Chile, Jens Andermann se refirió a algunos de los elementos recurrentes en los documentales de estos directores, afirmando que ponen en escena su orfandad afectiva y que a través del viaje realizan una puesta en errancia del antes inmóvil proceso de duelo. Contra la fijeza y seguridad del monumento, de la escritura o de los parques de la memoria, más propios de la generación anterior, directores como Albertina Carri o Nicolás Prividera producirán obras cinematográficas en las que será reiterado el uso del travelling y del plano secuencia, recursos que construyen un sentido de errancia y movilidad.

El sentido de movimiento que le confiere Andermann a esta elaboración de memoria no solo se remite a desplazamientos físicos, sino también a la transformación de las relaciones interpersonales. La performatividad que es inherente a todo acto testimonial aparece en estos documentales ligada a un proceso de elaboración del duelo que actúa sobre quienes realizan el acto de memoria. En el caso de Mi vida con Carlos, se torna evidente el cambio en la relación familiar: el documental produce una restauración de vínculos filiales que estaban suspendidos. Por su parte, en En algún lugar del cielo la directora se relaciona con amigos y compañeros de militancia que colaboran en la reinscripción de la figura de su padre en el espacio público. Practicar la memoria es "evitar que la historia se agote en la lógica del documento (el realismo denunciante que no admite juegos transfiguradores de significaciones) o el monumento (la contemplación nostálgica de lo heroizado, la reificación del pasado en bloques conmemorativos que petrifica el recuerdo como material inerte)" (Richard 11-12). En este sentido, ambas producciones sortean esta posibilidad de erigirse en documento o monumento y realizan una operación narrativa sobre los restos de la historia que recupera el valor de la experiencia del pasado.

En las dos películas, la heroicidad del combatiente que aparecía en una inicial retórica testimonial literaria es desplazada por la representación de imágenes más cotidianas y familiares. La masculinidad en el documental de Berger-Hertz, expresada en la voz del director, en la carta que dirige al padre y en el tipo de relaciones filiales con sus tíos es más bien íntima 
y en ocasiones sentimental. Aunque se afirme que Carlos "era un joven comunista ejemplar", es la madre y abogada Carmen Hertz la que encarna en el documental un personaje políticamente comprometido, racional y emocionalmente "inquebrantable". En este caso, el actor político es femenino y, como tal, pertenece al orden de las organizaciones de los derechos humanos, de los tribunales de justicia, en resumen, de lo público. A partir de esta figura se crea un acceso al ámbito público/político que coincide con el espacio y la voz de la madre, lo cual se ve tanto en la visita a la Vicaría de la Solidaridad como en las declaraciones a la prensa por los casos Caravana de la Muerte y Pinochet. Es interesante destacar que este personaje femenino se contrapone a otro fantasmático: la joven empleada de la casa Berger-Hertz que fuera degollada por los servicios secretos. Una conversación entre el hijo y la madre mientras caminan por Barcelona refiere esta historia ominosa. Si bien lo macabro entra en la casa, el tono emocional no alcanza a restaurar la identidad de esa mujer anónima: víctima extrema y sujeto sin historia ni imagen, cuya identidad no es restituida.

Aparejada a cierta despolitización ideológica del mundo representado, Mi vida con Carlos ha optado por una retórica emocional, un cierre en el círculo familiar, que sale hacia lo social a modo de cita de época. En estos sentidos, se contrapone con el documental de Carmona, donde la inflexión de la dimensión política se expresa en la presencia de la comunidad de militantes del MIR. Trozos de película presentan a Augusto Carmona en el contexto periodístico del canal de televisión de la Universidad de Chile, actualizándolo en un quehacer profesional. Por otra parte, las entrevistas a Horacio Marotta, Gladys Díaz y Angélica Álvarez recuperan una identidad militante que politiza su oficio durante la dictadura. El relato verbal de la militancia y la narración fílmica de los espacios de la clandestinidad son las dos claves que representan una dimensión de lo político, lo que establece un contrapunto con las escenas callejeras de manifestaciones en el Chile de la postdictadura. En estas escenas de conmemoración de los treinta años del golpe de Estado, lo político en la sociedad chilena se muestra deprimido: son voces reducidas, solitarias y envejecidas entre las que, sin embargo, encontramos personajes anónimos que devuelven un sentido histórico de carácter social. Pero se trata de un sentido que no le pertenece a la generación de hijos, la que enfatiza el carácter no ideológico de sus opciones de vida. Mientras el hermanastro de la directora señala que fue pionero porque estaba obligado, Paula Schopf, DJ de música electrónica 
e hija de una madre torturada, recalca que le gusta la música tecno porque es "poco ideológica", hecha para tener sensaciones. Estas afirmaciones hacen efectivo el alejamiento de las retóricas testimoniales de la generación precedente, subrayan el quiebre con una narrativa unívoca y las fisuras de los presupuestos ideológicos heredados, así como también refuerzan la mirada distanciada de quien no integra una colectividad (de hecho, Alejandra pasa como un observador no partícipe en la manifestación pública).

Estas representaciones de la colectividad y de la generación a la que pertenecían los padres contrastan con la autorrepresentación de una infancia traumática que queda obliterada. En su lugar aparece una imagen pública de niños que asumen una posición simbólica. Es así como vemos imágenes de archivo en las que ambos directores se muestran compelidos a actuar como adultos: Alejandra Carmona entra rodeada de niños alemanes a su colegio Salvador Allende, donde será protagonista de actos de solidaridad con Chile, ejerciendo una función política determinada por los adultos de la que renegará en la adolescencia (ver figura 2). Asimismo, en Mi vida con Carlos, Germán Berger-Hertz, con nueve años de edad, aparecerá entrevistado en un programa televisivo hablando de la muerte de su padre con un vocabulario y un distanciamiento poco comunes en el lenguaje infantil.

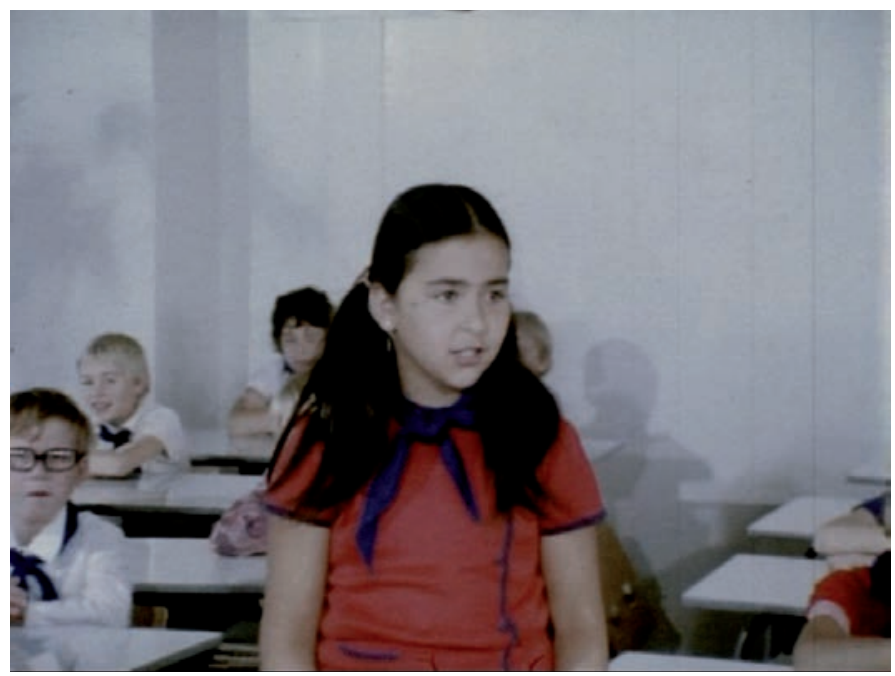

Figura 2. En algún lugar del cielo, de Alejandra Carmona 
Estas secuencias permiten entrever una experiencia infantil cuyo efecto traumático es silenciado en el presente de enunciación del documental. No obstante, es posible inferir que si "la primacía de la infancia en Freud nos descentra tan irremediablemente -y también tan antirreflexivamentecomo la extrañeza del inconsciente" (Laplanche citado en Butler 107), entonces, en estas películas, la autorrepresentación necesariamente expone la opacidad del $\mathrm{yo}^{5}$. Este descentramiento se relaciona metonímicamente con el movimiento de los sujetos testimoniales.

Desde esa condición errante, los documentales realizan una acción afirmativa, mediante la cual la transmisión de la experiencia intenta elidir los procesos de silenciamiento y no simbolización de la figura paterna. En el comienzo de Mi vida con Carlos dice la voz en off: "mi familia fuimos ella y yo, y entre nosotros, tu fantasma, tu figura heroica", lo que instala la escena del hijo con la madre en un modelo de "tercero presente" que se perpetúa durante toda la infancia. Ante la imposibilidad de elaborar el duelo, aparece la paralización o "rigidización" de las relaciones familiares, manifiesta inicialmente en el silenciamiento de los hermanos Berger. A lo largo del rodaje, el documental actúa sobre los participantes en un nivel psicológico, mediante la puesta en acto del proceso de desbloqueo y activación del trabajo de duelo, que comienza por hablar de aquello omitido y silenciado. Dice el tío Eduardo: "Germán tiene una idea muy buena que se trata que Ricardo, Carmen y yo conversemos todo lo que debimos haber conversado después del 19 de octubre de 1973". La ampliación de la relación filial a una relación familiar parece ser un mecanismo mediante el cual Berger-Hertz moviliza un trabajo de duelo en la escena ritual del abrazo de los tres hombres en el desierto.

Asimismo, la performatividad del testimonio documental actúa sobre las posibilidades de transmisión intergeneracional. Tanto En algún lugar del cielo como Mi vida con Carlos terminan con escenas en que las hijas de los directores dialogan con ellos sobre los abuelos. Mientras Berger-Hertz

5 Dice Butler que “el 'yo' que narra comprueba que no puede encauzar su relato, no puede describir su incapacidad de narrar ni decir por qué razón la narración se derrumba. Llega o, mejor, vuelve a sentirse radicalmente, si no irremediablemente, ignorante de quién es él mismo. A la sazón, el 'yo' no transmite ya un relato a un analista receptor u otro: monta una escena, recluta al otro con miras a la escena de su propia opacidad para sî” (97). 
actualiza la presencia vivificada de Carlos en la vida de sus hijas (a través del regalo que éste supuestamente les deja en el bosque), Carmona pregunta a la niña por el lugar en que se encuentra su abuelo ("en algún lugar del cielo"). Estas dos escenas proyectan finales inconclusos, que mantienen la elaboración del duelo en un estado de apertura.

Luego del análisis de En algún lugar del cielo y Mi vida con Carlos, se puede constatar la aparición de un nuevo testimonio, cuya novedad estaría marcada tanto por la posición de testigo elegida, como por los continuos desplazamientos y las operaciones formales que realiza. A partir de la autorrepresentación y el trabajo de la memoria sobre la propia biografía, se explota la factura misma del documental en su carácter performático que actúa sobre la elaboración del duelo. Ambos directores llevan a cabo una investigación y documentan las circunstancias de la muerte y desaparición de sus padres, reinscribiendo su figura individual en el ámbito público. Sin embargo, tanto la falta de un espacio social de reconocimiento como la demarcación del relato en torno a lo familiar limitan el trabajo de memoria a lo privado. Estos documentales se debaten entre una retórica inscrita en la metáfora filial y una búsqueda de la posibilidad de transmisión del trauma colectivo al proyectar un nuevo espectador.

\section{BiBLIOGRAFÍA}

Andermann, Jens. "Campo expandido: postdictadura y paisaje". Conferencia inédita. Santiago: USACh, 28 de abril de 2011.

BarriL, Claudia. Las imágenes que no me olvidan: cine documental autobiográfico y (pos)memorias de la Dictadura Militar chilena. Santiago: Cuarto Propio, 2013. Impreso.

Bossy, Michelle y Constanza Vergara. Documentales autobiográficos chilenos: memoria y autorrepresentación. Santiago: Fondo de Fomento Audiovisual del Consejo de la Cultura y las Artes, 2010. Impreso.

Beattie, Keith. "The camera I: Autobiographical Documentary". Documentary Screens: Non fiction Film and Television. New York: Palgrave Macmillan, 2004. 105-124. Impreso.

Berger-Hertz, Germán, dir. Mi vida con Carlos. Guión: Germán BergerHertz, Joaquim Jordá, Roberto Brodsky. Chile, 83 min, 2009. Filme. 
Bruss, Elizabeth W. "Eye for I: Making and Unmaking Autobiography in Film". Autobiography: Essays Theoretical and Critical. James Olney, ed. Princeton: Princeton University Press, 1980. 269-320. Impreso.

Butler, Judith. Dar cuenta de sí mismo. Madrid: Amorrortu, 2009. Impreso.

Carmona, Alejandra, dir. En algún lugar del cielo. Guión: Claudio Betsalel, Alejandra Carmona, Álvaro Ramírez. Chile, 70 min, 2003. Filme.

Donoso, Catalina. "Sobre algunas estrategias fílmicas para una propuesta de primera persona documental". Comunicación y medios 26 (2012): 2330. Impreso.

Firbas, Paul y Pedro Meira Monteiro. Andrés di Tella: cine documental y archivo personal. Conversación en Princeton. Buenos Aires: Siglo XXI, 2006. Impreso.

LACAPRA, DOMINICK. Escribir la historia, escribir el trauma. Barcelona: Nueva Visión, 2005. Impreso.

Lagos, PaOla. "Viajes de ida y retorno entre la pertenencia y el desarraigo. La construcción narrativa del hogar y la identidad en los diarios cinemautobiográficos de David Perlov". Revista Comunicación 10 (2012): 531-546. Impreso.

Lejeune, Philippe. "Cine y autobiografía, problemas de vocabulario". Cineastas frente al espejo. Gregorio Martín Gutiérrez, ed. Madrid: T \& B editores, 2008. 13-26. Impreso.

Llanos, Bernardita. "El documental de la generación postdictadura y su mirada al pasado: El edificio de los chilenos y Mi vida con Carlos". Conferencia inédita. Santiago: Facultad de Letras de la Pontificia Universidad Católica de Chile, 2013.

Molloy, Silvia. Acto de presencia. La escritura autobiográfica en Hispanoamérica. México: Fondo de Cultura Económica, 1996. Impreso.

Ramírez, Elizabeth. "Estrategias para (no) olvidar: notas sobre dos documentales chilenos de la post-dictadura". Aisthesis 47 (2010): 4563. Impreso.

Richard, Nelly, ed. Politicas y estéticas de la memoria. Santiago: Cuarto Propio, 2000. Impreso.

Sarlo, Beatriz. Tiempo pasado. Cultura de la memoria y giro subjetivo. Una discusión. Buenos Aires: Siglo XXI, 2005. Impreso. 